\title{
Thermal comfort analysis of hostels in National Institute of Technology Calicut, India
}

\author{
G K KUMAR LACHIREDDI ${ }^{1}$, P MUTHUKUMAR ${ }^{2, *}$ and SUDHAKAR SUBUDHI ${ }^{3}$ \\ ${ }^{1}$ Department of Mechanical Engineering, National Institute of Technology Calicut, Calicut 673601, India \\ ${ }^{2}$ Department of Mechanical Engineering, Indian Institute of Technology Guwahati, Guwahati 781039, India \\ ${ }^{3}$ Department of Mechanical and Industrial Engineering, Indian Institute of Technology Roorkee, \\ Roorkee 247667, India \\ e-mail: ganga@nitc.ac.in; pmkumar@iitg.ernet.in
}

MS received 3 April 2014; revised 9 May 2016; accepted 12 July 2016

\begin{abstract}
Thermal comfort study was carried out in the hostels of National Institute of Technology Calicut, Kerala, which is located in a warm humid climatic zone of India. Measurements of ambient temperature, globe temperature, relative humidity, air velocity and illuminance were carried out in eight hostels, and in parallel a paper-based survey was conducted among students to know about their Thermal Preference Vote (TPV) and Thermal Sensation Vote (TSV) based on an ASHRAE seven-point scale. Predicted Mean Vote (PMV) and Predicted Percentage Dissatisfied (PPD) have been evaluated based on Fanger's theory of thermal comfort by utilizing the field measurements. Preferred operative temperature and neutral effective temperature were obtained based on the Predicted Mean Vote (PMV). Similarly the preferred operative temperature and neutral effective temperature were identified, for both Thermal Sensation Vote (TSV) and Thermal Preference Vote (TPV). Thermal comfort conditions for $80 \%$ satisfaction were also determined in each case. Correlations between the Predicted Mean Vote (PMV) and the Thermal Sensation Vote (TSV) as well as between the Predicted Mean Vote (PMV) and the Thermal Preference Vote (TPV) were obtained.
\end{abstract}

Keywords. Hostel; Predicted Mean Vote (PMV); Predicted Percentage Dissatisfied (PPD); adaptive thermal comfort; operative temperature; effective temperature.

\section{Introduction}

\subsection{Necessity}

India is a country with population of 1210 million, about $67 \%$ of which are under the age 35 years [1]. A total of 169.75 lakh students were enrolled in higher education in the academic year 2011; 26.15 lakh of them were enrolled in technical education [2]. Majority of this young population of India lives away from homes, either in institute hostels or in private hostels, for the purpose of education. This scenario is the most common in students aspiring for, and pursuing, engineering and medical courses. Very few studies are available to indicate the thermal comfort, which has a major impact on the performance of students in the hostels.

Ministry of Human Resource Development, Government of India, aims to double the gross enrollment ratio in higher education to $30 \%$ [3] against $15 \%$ at present, by the end of the 12th 5-year plan (2012-2017). This indicates that the hostels and related infrastructure will be double by the end

*For correspondence of the 12th 5-year plan. Proper guidelines for thermal comfort in hostels are to be provided for designers, not only to maintain adequate comfort levels but also to reduce the energy needs. These guidelines will be established only by conducting thermal comfort surveys along with field measurements in the existing hostels, which will provide an insight for the building designers.

\subsection{Adaptive comfort model}

In 1970, Fanger developed a thermal comfort model called "Fanger's PMV model" based on laboratory experiments conducted in climate chambers. Four physical variables, namely air temperature, air velocity, mean radiant temperature and relative humidity, along with two personal variables, namely clothing and activity level, were considered in Fanger's PMV model. Consequent works by Dear and Brager [4], Nicol [5], Nicol and Humphreys [6] and Fanger and Toftum [7] suggested the importance of adaptive thermal comfort model over Predicted Mean Vote (PMV) model as the latter failed in exact prediction of actual thermal sensation in naturally ventilated buildings. Thermal comfort conditions of 
people living in naturally ventilated buildings depend not only on physiological aspects but also on adaptive nature and psychological aspects. Because of this reason Fanger's theory failed in predicting thermal comfort conditions in naturally ventilated buildings $[4,6]$.

Nicol and Humphreys [6] suggested several guidelines for adaptive thermal comfort and sustainable thermal standards for buildings based on the available field data. By considering the importance of adaptive comfort theory in the naturally ventilated buildings, an expectancy factor was suggested to extend the Predicted Mean Vote (PMV) model [7], and ASHRAE revised the ASHARE standard 55 by incorporating a new adaptive comfort standard [4]. Later, Nicol [5] suggested ways to complement the international standards by incorporating adaptive comfort standards obtained from the local field surveys. Recently Yao et al [8] proposed a new Adaptive Predicted Mean Vote (aPMV) model, introducing an adaptive coefficient, to take care of adaptive factors.

Adaptive comfort model [9] is the best standard to predict the thermal comfort in naturally ventilated buildings and suggested not to use Predicted Mean Vote (PMV) model even with the expectancy factor is recommended [10]. Physiological, psychological and behavioural adaptations play their role in adaptive comfort model [11], which would be better evaluated by complementing the international standards with local comfort surveys. Local comfort surveys are needed in evaluating the adaptive comfort model specific to the region [5]. These local comfort surveys are very much essential in tropical countries like India, where the standards based on the adaptive comfort model are not established.

\subsection{Thermal comfort studies in India}

Thermal comfort studies reported in India are very few and mainly concentrated in prediction of thermal comfort conditions in vernacular buildings of north-east India [12-14], vernacular building in Kerala [15-19], vernacular building in coastal area of Nagapattinam, Tamilnadu [20], modern buildings and apartments in Chennai and Hyderabad [21-26], hostels and institute/office buildings in Hyderabad and Jaipur [27, 28] and a few more studies include study at a Chennai railway terminal [29] and primary school in Chennai [30].

Recently, Mishra and Ramgopal [31] analysed the available adaptive comfort models and suggested the use of comfort model given by EN15251 for predicting adaptive thermal comfort conditions of the tropical regions of India. This indicates that in India there is a dearth of local field studies to establish standards based on adaptive comfort model. Moreover, only Dili and their team conducted thermal comfort analysis of a vernacular building and a modern building in Mallapuram district of Kerala, and concluded that vernacular building performs better than modern building in providing thermal comfort.
Data available to date, from various thermal comfort studies detailed above, are limited and lot more studies are needed for establishing the thermal comfort standards in the state of Kerala. In the present work, an outcome of thermal comfort studies in the hostels of National Institute of Technology (NIT) Calicut, Kerala, located in a warm and humid climatic zone is detailed.

\section{Objectives}

The following are the objectives of the present work.

(i) To evaluate the thermal comfort conditions in eight hostels, located in a warm and humid climatic zone, by conducting both field measurements as well as paper-based survey.

(ii) To establish a correlation between

a. Predicted Mean Vote (PMV) and Thermal Sensation Vote (TSV).

b. Predicted Mean Vote (PMV) and Thermal Preference Vote (TPV).

(iii) To find neutral effective temperature and preferred operative temperature based on Predicted Mean Vote (PMV), Thermal Sensation Vote (TSV) and Thermal Preference Vote (TPV).

\section{Methodology}

\subsection{Details of site and period of survey}

NIT Calicut is a technical institute of national importance located at the foothills of Western Ghats, Kerala, India. It is located in a warm and humid climatic zone of India and its geographical coordinates are $11^{\circ} 15^{\prime}$ north, $75^{\circ} 46^{\prime}$ east. The campus is spread over an area of 1,200,000 $\mathrm{m}^{2}$ and includes an academic zone, hostel zone, residential zone and sports zone. The institute houses about 6000 students and 300 families. Figure 1 shows a plan view of the campus.

Calicut city is located towards the northern part of Kerala at the coastline of Arabian Sea. Here rainy season is severe and lasts for a period of 6 months in a year, starts with south-west monsoon from June to August and ends with north-east monsoon from September to November. Summer season is moderate and lasts for 4 months in a year from February to May. Even though the temperatures in summer are not very high, the presence of high humidity levels causes severe discomfort during this period. Winter season is comfortable with slightly cool nights and lasts for 2 months from December to January. Temperature varies from 23 to $31^{\circ} \mathrm{C}$ during the rainy season, $25-34^{\circ} \mathrm{C}$ during the summer season and $21-30^{\circ} \mathrm{C}$ during the winter season. Relative humidity varies from 70 to $90 \%$ during the rainy 


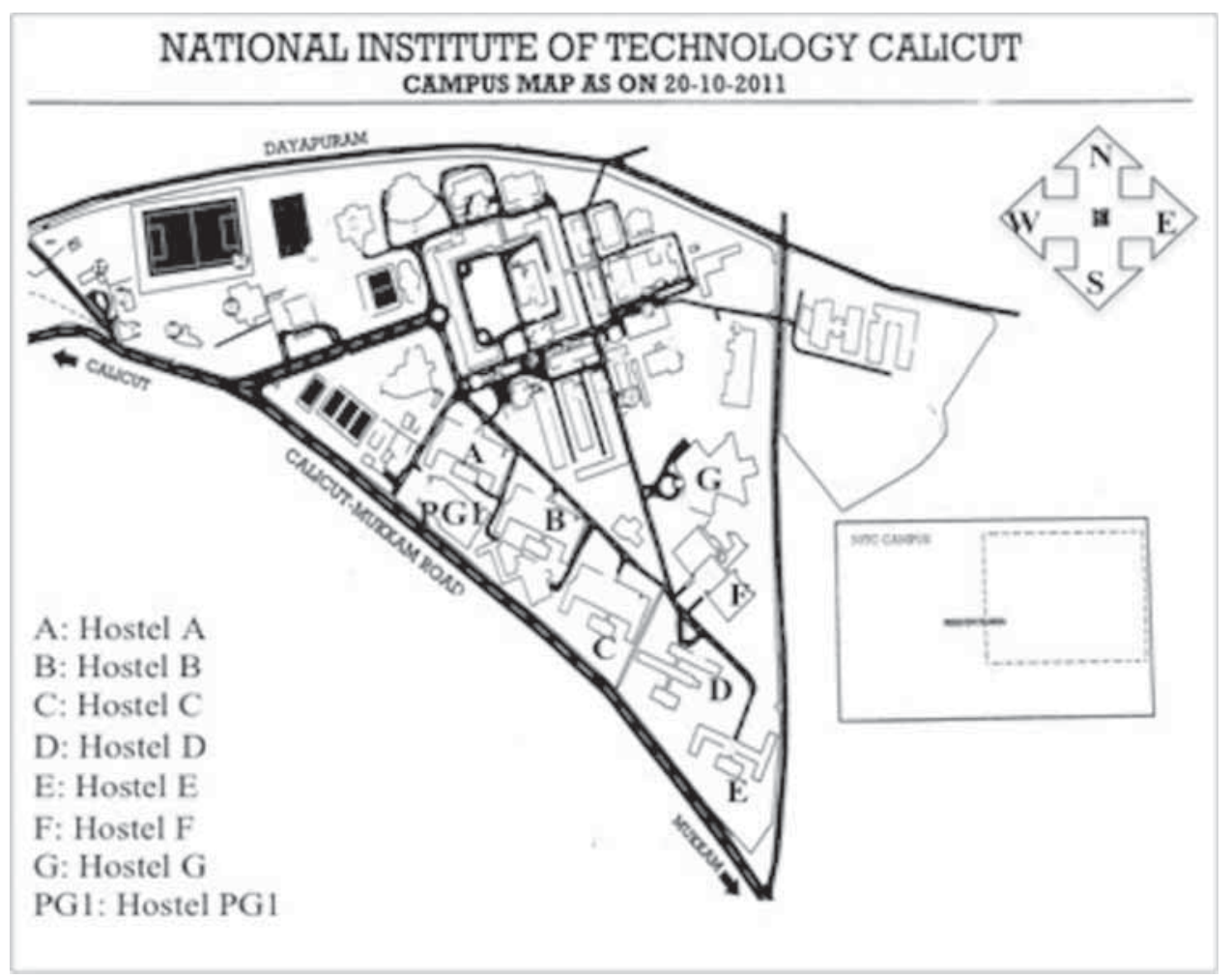

Figure 1. Campus map of NIT Calicut.

season, 64-80\% during the summer season and 53-65\% during the winter season.

Among all the seasons in this area, summer season is the only season that causes a major discomfort due to the presence of high relative humidity at elevated temperatures. Since the temperatures of this region are not very high comfort levels would be achieved by maintaining proper ventilation, which negates the effect of high relative humidity. To know the comfort levels in the hostels of NIT Calicut during summer, it was decided to carry out a thermal comfort analysis of the hostels for the period of summer 2013.

A total of eight hostels, namely A-G and PG1, were considered for the study and locations of these hostels are indicated in figure 1. Results discussed in this paper include the outcome of both field measurements and questionnaire survey, conducted for the period of 4 months during summer 2013. A questionnaire survey as well as field measurements were carried out simultaneously for the 4 months February, March, April and May of summer 2013 to analyse the data obtained from both subjective and objective means.

\subsection{Field measurements}

Field measurements include ambient temperature $\left(T_{\mathrm{a}}\right)$, globe temperature $\left(T_{\mathrm{g}}\right)$, air velocity $(V)$, relative humidity $(\mathrm{RH})$ and illuminance made using the Comfort Evaluation
System, which is shown in figure 2. Comfort Evaluation System was set to $\log$ the measured variables to a memory module continuously with a time step of $15 \mathrm{~min}$. ASHRAE standards were followed during the entire course of measurements. All the sensors were properly installed at three different positions $(0.1,0.6$ and $1.2 \mathrm{~m})$ above the floor level for each measured parameter except globe temperature. Globe temperature sensors were placed in two positions at 0.4 and $1.2 \mathrm{~m}$ above the floor level. Operative temperature $\left(T_{\mathrm{op}}\right)$ was determined by considering average of ambient temperature $\left(T_{\mathrm{a}}\right)$ and globe temperature $\left(T_{\mathrm{g}}\right)$. Effective temperature $\left(\mathrm{ET}^{*}\right)$ is the temperature at $50 \%$ relative humidity that yields the same effect as in the actual environment. PMV and PPD were evaluated as explained in ASHRAE fundamentals 2009.

Measurements were taken in each hostel for 14 days spreading over the entire period February-May in summer 2013 by using the Comfort Evaluation System. Measurements were carried out in each hostel for seven rounds with a span of 2 days in each round. In every round of measurements, the Comfort Evaluation System was installed for 2 days in each hostel and it took a total of 17 days per round for completing the measurements in all eight hostels. Measurements were carried out in a cyclic order starting from Hostel A and ending with Hostel PG1 through Hostels $\mathrm{B}-\mathrm{G}$ in each round. It took a total of 17 days to complete each round of measurements and took nearly 125 days to complete all the seven rounds of measurements. 


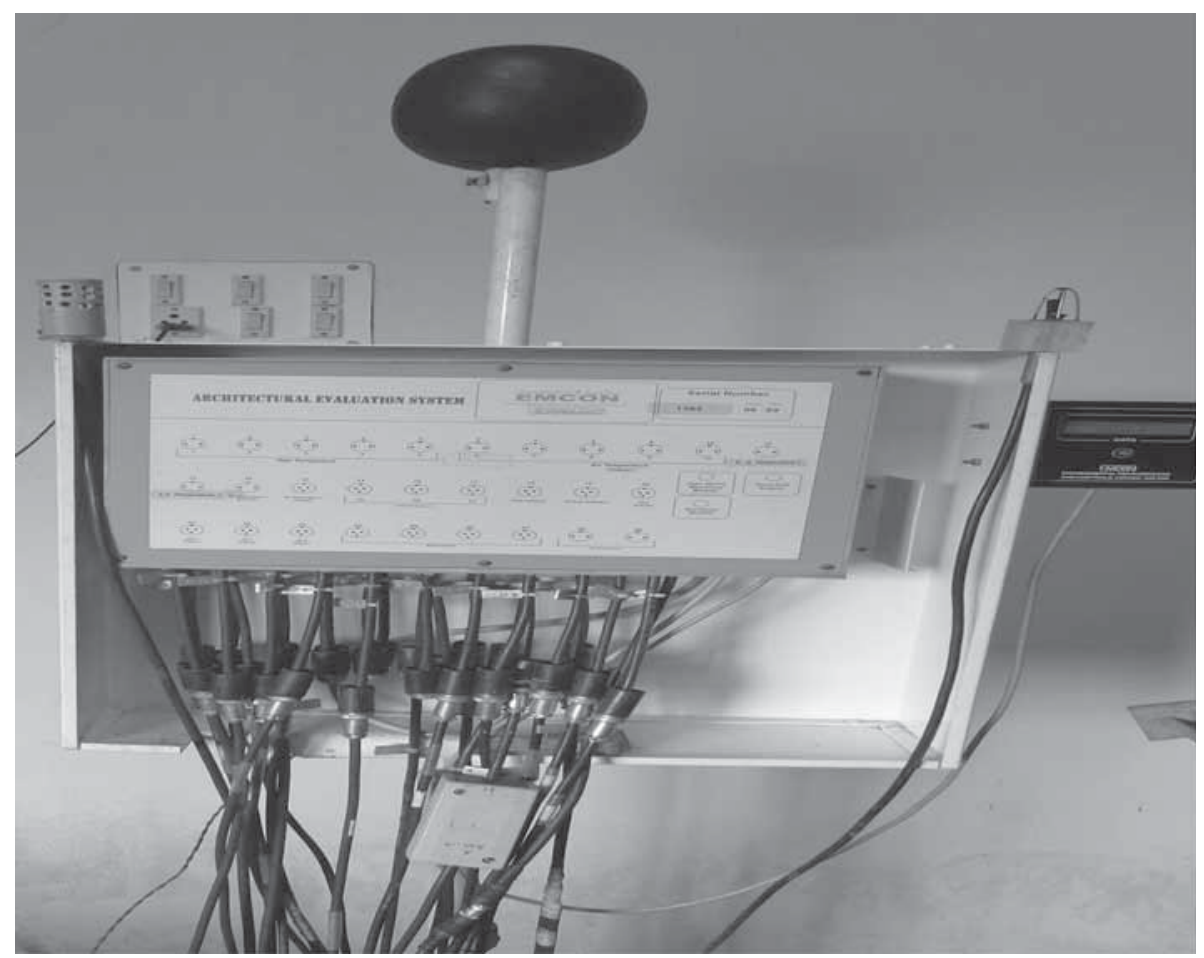

Figure 2. Comfort evaluation system.

\subsection{Survey}

A survey was conducted during the months of FebruaryMay in summer 2013 by distributing questionnaires among the students, of age group 17-25 years. Both the field measurements and survey were carried out simultaneously. After careful observation of their clothing pattern, clothing resistance is fixed as 0.4 CLO since the majority of subjects were found wearing T-shirts and shorts that results in a clothing resistance of 0.4 CLO. Metabolic activity is considered as 1 MET since the subjects were sitting and filling the questionnaire during the survey. Both the clothing insulation level and metabolic rates were evaluated with the help of ASHRAE data.

Complete survey along with field measurements were conducted in seven rounds. The Comfort Evaluation System was installed in the top floor of hostels for first, fourth and seventh rounds of measurements, in the middle floor of hostels during second and fifth rounds of measurements and in the ground floor of hostels during third and sixth rounds of measurements. Simultaneously, a paper-based survey was also conducted among the students. A total of around 1000 questionnaires were distributed among the students during the period of field measurements. In return a total of 735 questionnaires with responses were received.

Mean values of various field measurements, details of survey related to Thermal Sensation Vote (TSV) and details of survey related to Thermal Preference Vote (TPV) for eight hostels are presented in tables 1, 2 and 3, respectively. Thermal comfort conditions of each hostel based on PMV, TSV and TPV are also mentioned in each tabular form. Average value of votes falling between -0.5 and $+0.5,0.5$ deviation on either side from the neutral point of thermal sensation scale, is considered as the comfort zone. Similarly average vote falls in the range less than $-2.5,-2.5$ to -1.5 , -1.5 to $-0.5,0.5-1.5,1.5-2.5$ and greater than 2.5 on the thermal sensation scale are considered as cold, cool, slightly cool, slightly warm, warm and hot conditions, respectively. Two main questions of the survey questionnaire along with ASHRAE thermal sensation scale are provided in "Appendix".

\section{Results and discussion}

\subsection{Percentage dissatisfied (PD) based on PMV, $T S V$ and TPV}

Predicted Mean Vote (PMV) and Predicted Percentage Dissatisfied (PPD) were calculated using Fanger's theory of thermal comfort by utilizing the data obtained from the field measurements. Thermal Sensation Vote (TSV) was based on the ASHRAE seven-point scale obtained from the survey. Percentage dissatisfied in case of Thermal Sensation Vote (TSV) is obtained by utilizing the relation between Predicted Mean Vote (PMV) and Predicted Percentage Dissatisfied (PPD). Similarly with the help of 
Table 1. Details of field measurements of hostels.

\begin{tabular}{lccccr}
\hline Hostel & Number of participants & MET & CLO & $T_{\text {op }}\left({ }^{\circ} \mathrm{C}\right)$ & 31.22 \\
\hline A & 75 & 1.0 & 0.4 & 32.21 & 33.01 \\
B & 119 & 1.0 & 0.4 & 31.76 & 31.71 \\
C & 23 & 1.0 & 0.4 & 32.32 \\
D & 128 & 1.0 & 0.4 & 33.13 \\
E & 126 & 1.0 & 0.4 & 31.68 & 33.61 \\
F & 79 & 1.0 & 0.4 & 34.41 \\
G & 132 & 1.0 & 0.4 & 31.4 \\
PG1 & 53 & 1.0 & 0.4 & 33.58 \\
\hline
\end{tabular}

Field survey was conducted during the months of February-May in summer 2013.

Table 2. Details of survey based on TSV for hostels.

\begin{tabular}{|c|c|c|c|c|c|c|c|c|}
\hline \multirow[b]{2}{*}{ Hostel } & \multirow[b]{2}{*}{$T_{\mathrm{op}}\left({ }^{\circ} \mathrm{C}\right)$} & \multicolumn{7}{|c|}{ Thermal sensation vote based on ASHRAE scale } \\
\hline & & Cold & Cool & Slightly cool & Neutral & Slightly warm & Warm & Hot \\
\hline A & 31.22 & 0 & 0 & 0 & 48 & 16 & 8 & 3 \\
\hline $\mathrm{B}$ & 32.21 & 0 & 0 & 0 & 29 & 53 & 26 & 11 \\
\hline $\mathrm{C}$ & 31.76 & 0 & 0 & 0 & 7 & 11 & 4 & 1 \\
\hline $\mathrm{D}$ & 31.71 & 0 & 0 & 0 & 42 & 64 & 17 & 5 \\
\hline $\mathrm{E}$ & 32.32 & 0 & 0 & 0 & 33 & 49 & 35 & 9 \\
\hline $\mathrm{F}$ & 30.13 & 0 & 0 & 0 & 64 & 12 & 3 & 0 \\
\hline G & 31.68 & 0 & 0 & 0 & 57 & 39 & 27 & 9 \\
\hline PG1 & 32.81 & 0 & 0 & 0 & 5 & 7 & 31 & 10 \\
\hline
\end{tabular}

Field survey was conducted during the months of February-May in summer 2013.

Table 3. Details of survey based on TPV for hostels.

\begin{tabular}{lccccc}
\hline & & & \multicolumn{2}{c}{ Thermal preference vote (TPV) } \\
\cline { 3 - 5 } Hostel & Number of participants & $T_{\text {op }}\left({ }^{\circ} \mathrm{C}\right)$ & Cooler than present & Present climate & Warmer than present \\
\hline A & 75 & 31.22 & 22.26 & 77.74 & 0 \\
B & 119 & 32.21 & 35.3 & 73.7 & 0 \\
C & 23 & 31.76 & 26.33 & 77.22 & 0 \\
D & 128 & 31.71 & 22.78 & 55.74 & 0 \\
E & 126 & 32.32 & 44.26 & 90.92 & 0 \\
F & 79 & 30.13 & 9.08 & 71.55 & 0 \\
G & 132 & 31.68 & 28.45 & 29.53 & 0 \\
PG1 & 53 & 32.81 & 70.47 &
\end{tabular}

Field survey was conducted during the months of February-May in summer 2013.

PMV-PPD relation, Thermal Preference Vote (TPV) is estimated on the seven-point scale by utilizing percentage dissatisfaction obtained from the survey.

Figures 3, 4 and 5 illustrate the percentage dissatisfied based on Predicted Mean Vote (PMV), Thermal Sensation Vote (TSV) and Thermal Preference Vote (TPV), respectively. Percentage dissatisfied was found to be $50-95 \%$ in case of Predicted Mean Vote (PMV), 5-70\% in case of Thermal Sensation Vote (TSV) and $10-70 \%$ in case of
Thermal Preference Vote (TPV). Percentage dissatisfied based on Predicted Mean Vote (PMV) predicted 25-45\% more dissatisfaction than that of Thermal Sensation Vote (TSV) and Thermal Preference Vote (TPV), which upholds the adaptive thermal comfort theory. Details of percentage dissatisfied and thermal comfort in eight hostels based on Predicted Mean Vote (PMV), Thermal Sensation Vote (TSV) and Thermal Preference Vote (TPV) are given in tables 4,5 and 6 , respectively. 


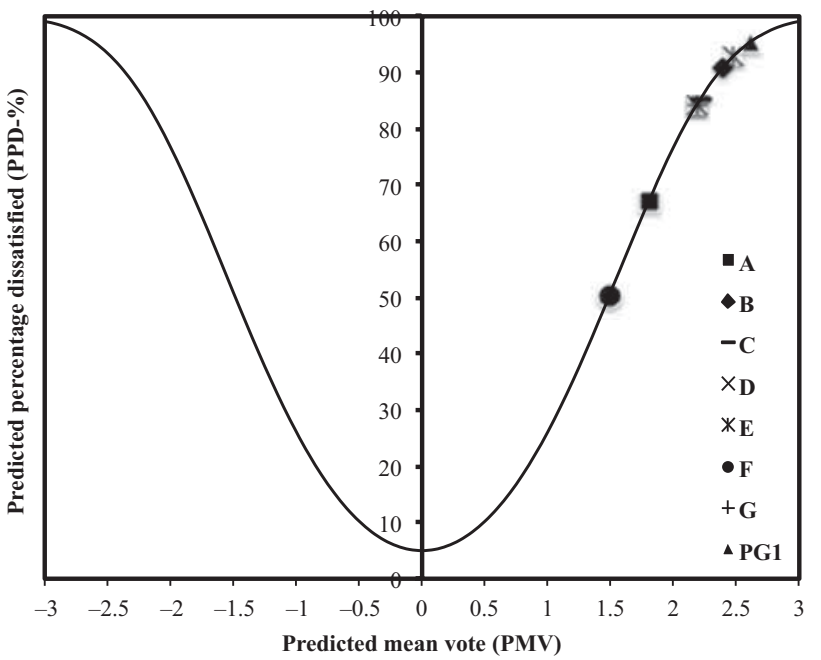

Figure 3. PMV-based percentage dissatisfied in eight hostels.

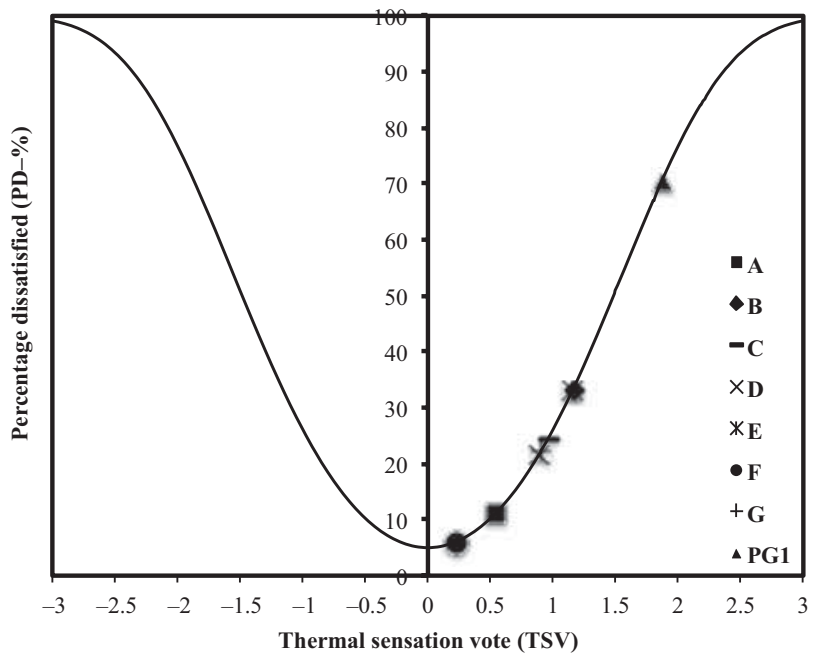

Figure 4. TSV-based percentage dissatisfied in eight hostels.

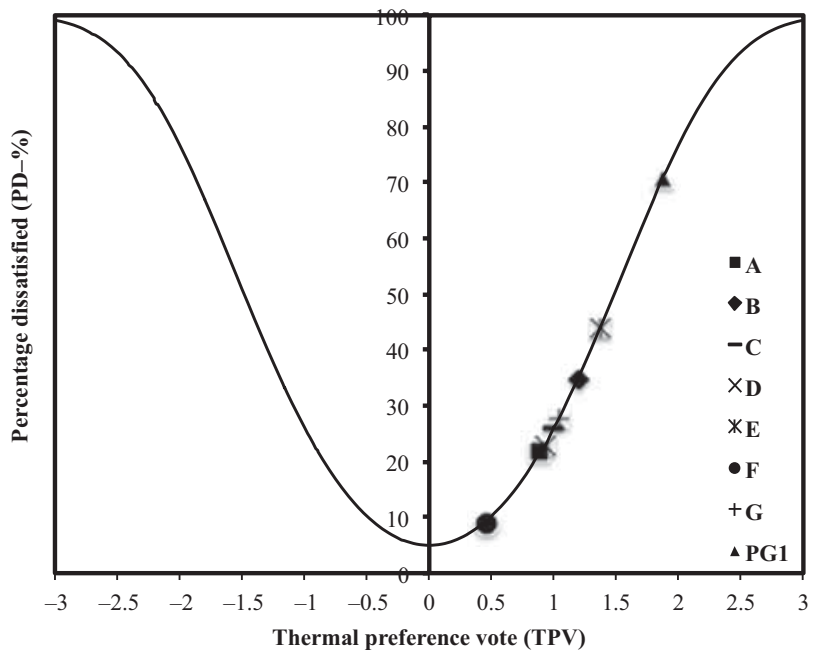

Figure 5. TPV-based percentage dissatisfied in eight hostels.

\subsection{Correlations to calculate TSV and TPV}

Linear regression analysis was carried out for Predicted Mean Vote (PMV) and Thermal Sensation Vote (TSV) as well as for Predicted Mean Vote (PMV) and Thermal Preference Vote (TPV). A linear equation between Predicted Mean Vote (PMV) and Thermal Sensation Vote (TSV) was obtained by the regression analysis as PMV $=0.746 *$ $\mathrm{TSV}+1.454$. It shows a strong correlation with $R^{2}=0.92$. The linear equation $\mathrm{PMV}=0.852 * \mathrm{TPV}+1.239$ was obtained in case of Predicted Mean Vote (PMV) and Thermal Preference Vote (TPV) with a strong correlation with $R^{2}=0.856$. Figures 6 and 7 illustrate the fit between Predicted Mean Vote (PMV) and Thermal Sensation Vote (TSV), and Predicted Mean Vote (PMV) and Thermal Preference Vote (TPV), respectively.

Table 4. Thermal comfort conditions of hostels based on PMV.

\begin{tabular}{lccccc}
\hline Hostel & $\begin{array}{c}T_{\text {op }} \\
\left({ }^{\circ} \mathrm{C}\right)\end{array}$ & $\begin{array}{c}\mathrm{ET}^{*} \\
\left({ }^{\circ} \mathrm{C}\right)\end{array}$ & PMV & $\begin{array}{c}\text { PPD } \\
(\%)\end{array}$ & $\begin{array}{c}\text { Thermal } \\
\text { comfort }\end{array}$ \\
\hline A & 31.22 & 33.01 & 1.80 & 67.31 & Warm \\
B & 32.21 & 34.26 & 2.38 & 90.68 & Warm \\
C & 31.76 & 33.68 & 2.21 & 85.29 & Warm \\
D & 31.71 & 33.61 & 2.18 & 84.40 & Warm \\
E & 32.32 & 34.41 & 2.46 & 92.73 & Warm \\
F & 30.13 & 31.4 & 1.49 & 50.60 & Slightly warm \\
G & 31.68 & 33.58 & 2.18 & 84.20 & Warm \\
PG1 & 32.81 & 35.07 & 2.68 & 96.47 & Hot \\
\hline
\end{tabular}

Table 5. Thermal comfort conditions of hostels based on TSV.

\begin{tabular}{lccrrc}
\hline Hostel & $T_{\text {op }}\left({ }^{\circ} \mathrm{C}\right)$ & $\mathrm{ET}^{*}\left({ }^{\circ} \mathrm{C}\right)$ & $\mathrm{TSV}$ & $\mathrm{PD}(\%)$ & Thermal comfort \\
\hline A & 31.22 & 33.01 & 0.55 & 11.26 & Slightly warm \\
B & 32.21 & 34.26 & 1.16 & 33.30 & Slightly warm \\
C & 31.76 & 33.68 & 0.96 & 24.33 & Slightly warm \\
D & 31.71 & 33.61 & 0.88 & 21.78 & Slightly warm \\
E & 32.32 & 34.41 & 1.16 & 33.26 & Slightly warm \\
F & 30.13 & 31.4 & 0.23 & 6.08 & Comfort \\
G & 31.68 & 33.58 & 0.91 & 22.45 & Slightly warm \\
PG1 & 32.81 & 35.07 & 1.87 & 70.47 & Warm \\
\hline
\end{tabular}

Table 6. Thermal comfort conditions of hostels based on TPV.

\begin{tabular}{lccccc}
\hline Hostel & $T_{\text {op }}\left({ }^{\circ} \mathrm{C}\right)$ & $\mathrm{ET}^{*}\left({ }^{\circ} \mathrm{C}\right)$ & $\mathrm{TPV}$ & $\mathrm{PD}(\%)$ & Thermal comfort \\
\hline A & 31.22 & 33.01 & 0.89 & 22.26 & Slightly warm \\
B & 32.21 & 34.26 & 1.19 & 35.3 & Slightly warm \\
C & 31.76 & 33.68 & 1.00 & 26.33 & Slightly warm \\
D & 31.71 & 33.61 & 0.93 & 22.78 & Slightly warm \\
E & 32.32 & 34.41 & 1.37 & 44.26 & Slightly warm \\
F & 30.13 & 31.4 & 0.46 & 9.08 & Comfort \\
G & 31.68 & 33.58 & 1.05 & 28.45 & Slightly warm \\
PG1 & 32.81 & 35.07 & 1.87 & 70.47 & Warm \\
\hline
\end{tabular}




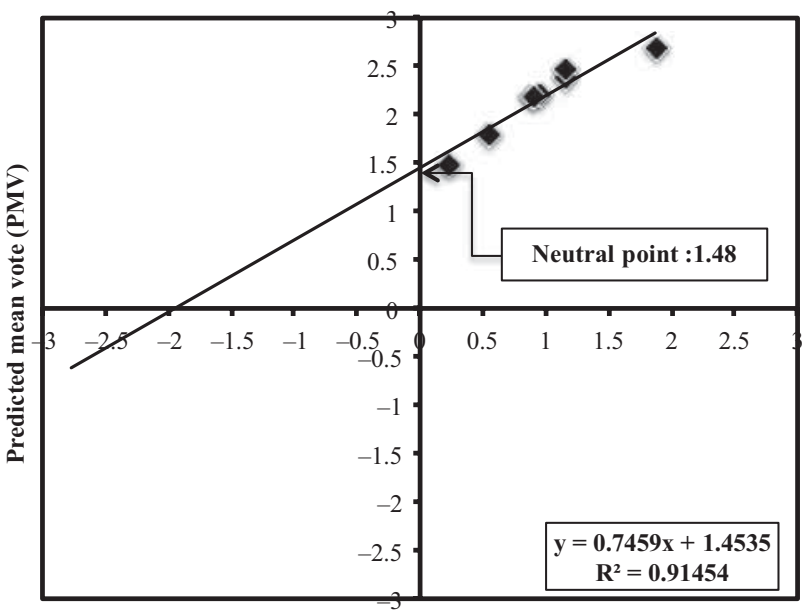

Thermal sensation vote (TSV)

Figure 6. Correlation between PMV and TSV.

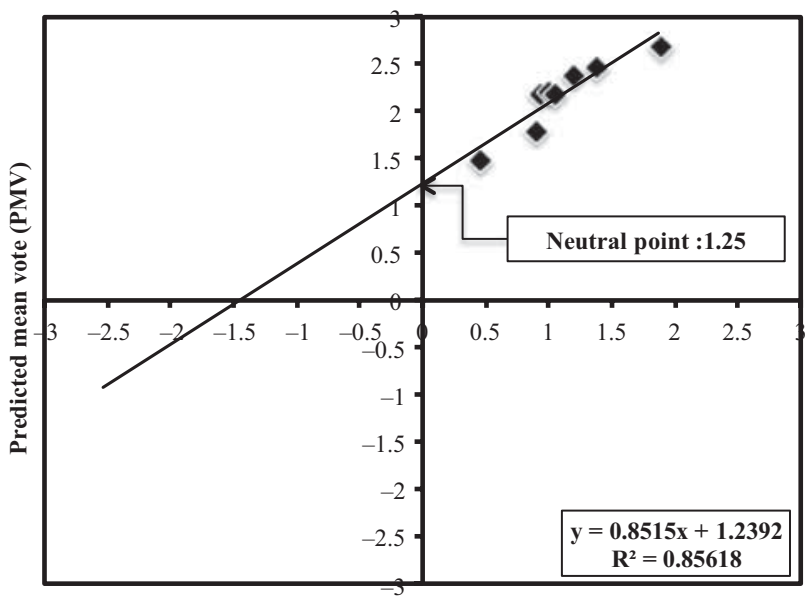

Thermal preference vote (TPV)

Figure 7. Correlation between PMV and TPV.

From the above discussion, it is clear that both Thermal Sensation Vote (TSV) and Thermal Preference Vote (TPV) show similar results with a slight variation whereas the Predicted Mean Vote (PMV) analysis demanded more thermal comfort than that of the actual. The shift of neutral point in ASHRAE seven-point scale was also identified, as +1.48 for Thermal Sensation Vote (TSV) and +1.25 for Thermal Preference Vote (TPV), in comparison to Predicted Mean Vote (PMV).

\subsection{Preferred operative temperature based on PMV, TSV and TPV}

Figures 8, 9 and 10 depict the variation of Predicted Mean Vote (PMV), Thermal Sensation Vote (TSV) and Thermal

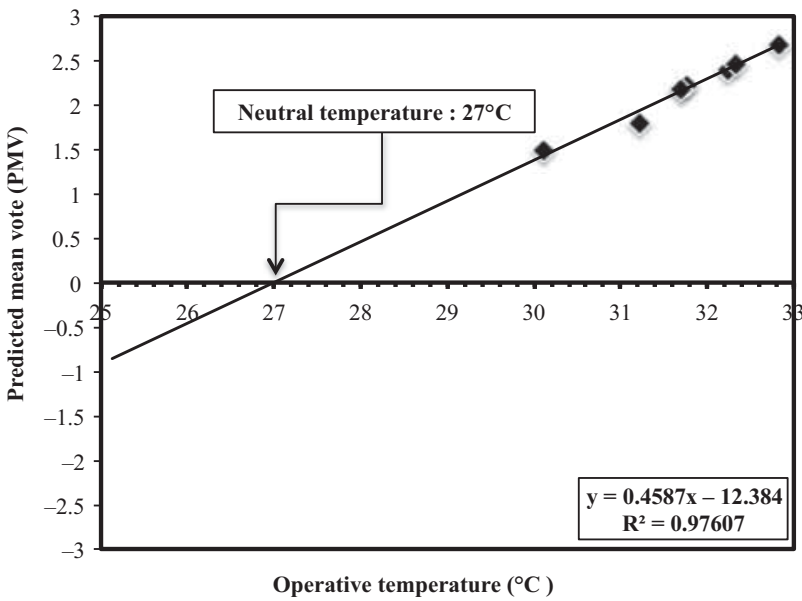

Figure 8. Variation of PMV with operative temperature.

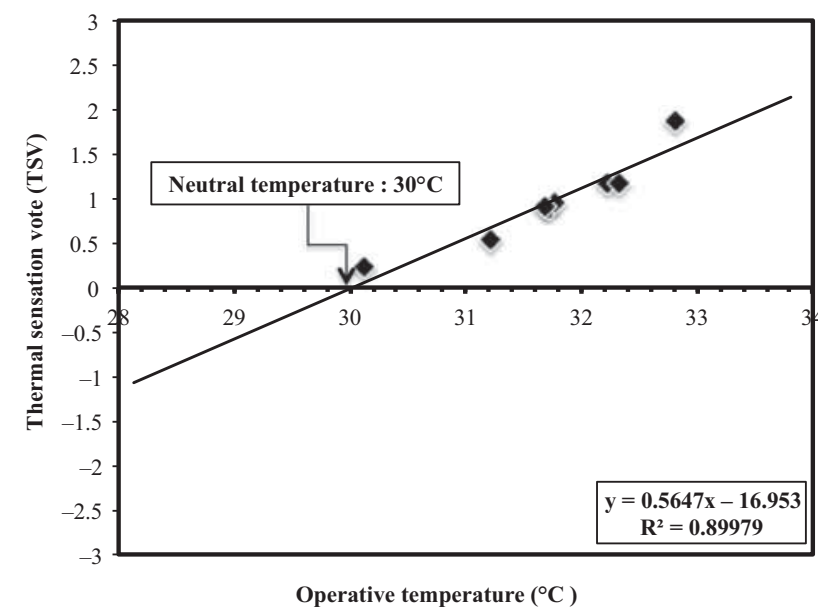

Figure 9. Variation of TSV with operative temperature.

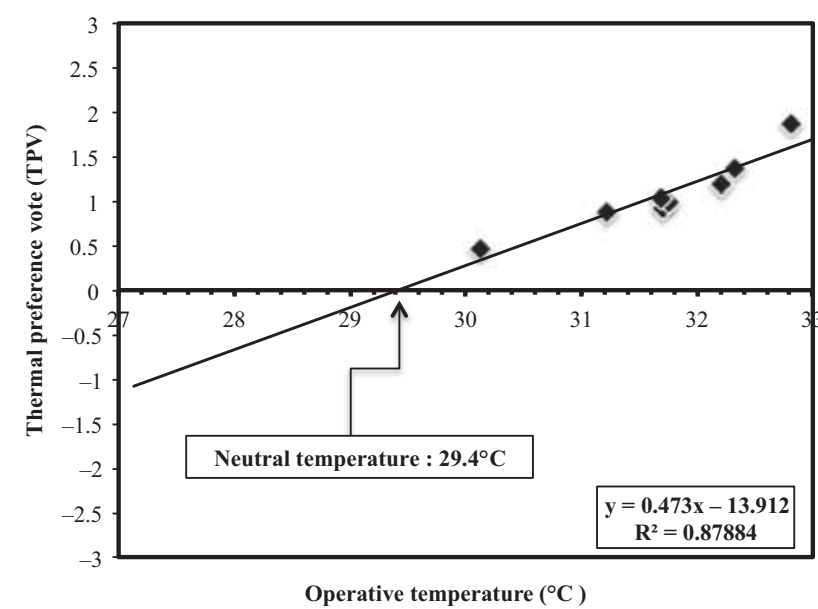

Figure 10. Variation of TPV with operative temperature. 
Preference Vote (TPV), respectively, with the change of operative temperature. It was observed that Predicted Mean Vote (PMV) failed in predicting the required thermal comfort conditions and showed the preferred operative temperature as $27^{\circ} \mathrm{C}$, which is nearly $3^{\circ} \mathrm{C}$ less than that obtained from either Thermal Sensation Vote (TSV) or Thermal Preference Vote (TPV). Preferred operative temperatures obtained based on Thermal Sensation Vote (TSV) and Thermal Preference Vote (TPV) were 30 and $29.4^{\circ} \mathrm{C}$, respectively, and the variation among these preferred temperatures is limited to $0.6^{\circ} \mathrm{C}$ only. Hence either Thermal Sensation Vote (TSV) or Thermal Preference Vote (TPV) can be used for predicting the thermal comfort in naturally ventilated hostels.

\subsection{Neutral effective temperature based on PMV, $T S V$ and TPV}

Figures 11, 12 and 13 show the variation of Predicted Mean Vote (PMV), Thermal Sensation Vote (TSV) and Thermal Preference Vote (TPV) respectively with the change of effective temperature. Neutral effective temperatures obtained based on Thermal Sensation Vote (TSV) and Thermal Preference Vote (TPV) were 31.3 and $30.4^{\circ} \mathrm{C}$, respectively, and the variation among these preferred temperatures is limited to $0.9^{\circ} \mathrm{C}$ only. However, in case of Predicted Mean Vote (PMV), the neutral effective temperature was identified as $27.2^{\circ} \mathrm{C}$ and is nearly $4^{\circ} \mathrm{C}$ less than that obtained from Thermal Sensation Vote (TSV). Hence adaptive comfort theory is the best suitable for predicting the thermal comfort conditions of naturally ventilated hostels in warm and humid climatic zone.

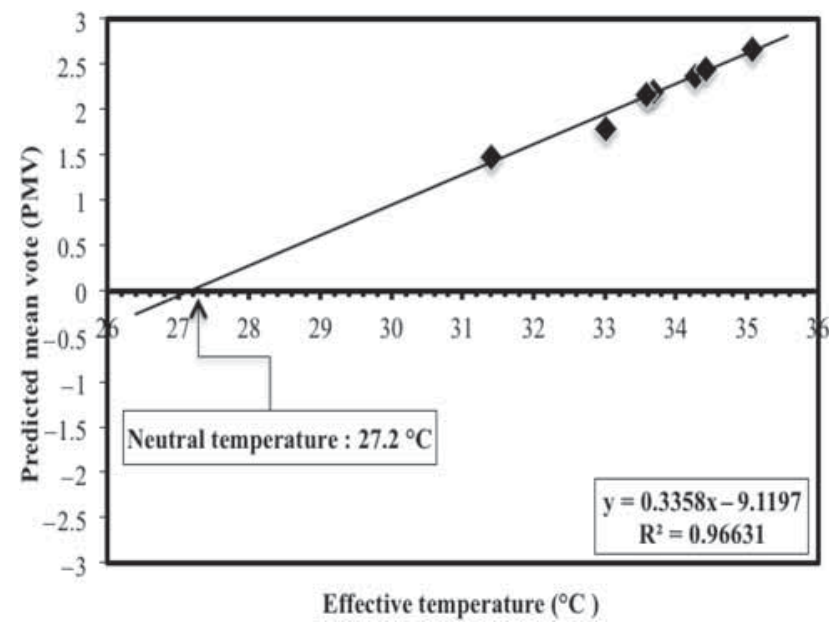

Figure 11. Variation of PMV with effective temperature.

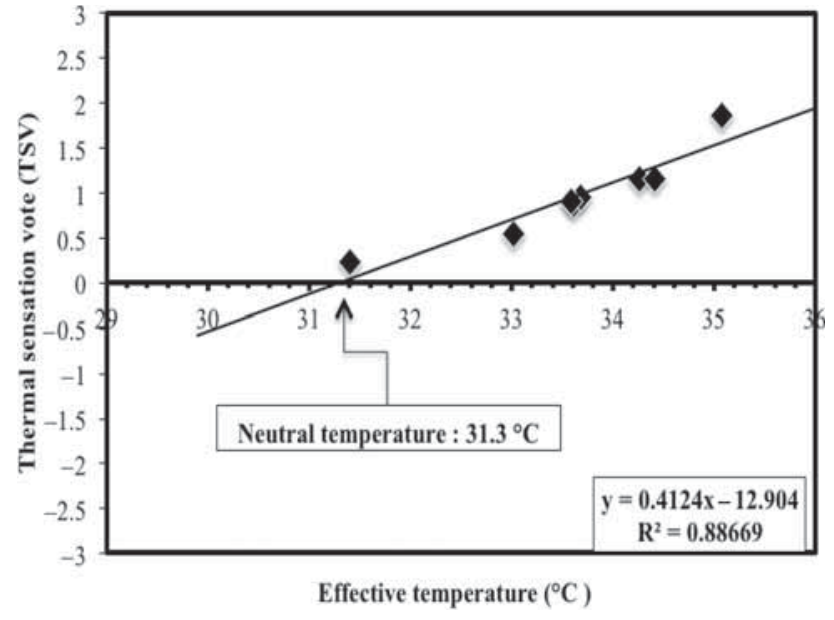

Figure 12. Variation of TSV with effective temperature.

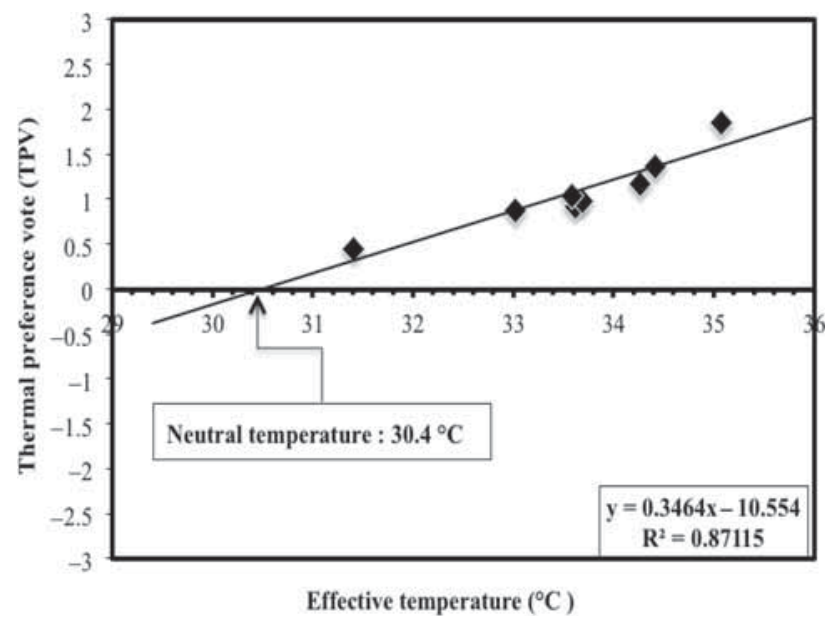

Figure 13. Variation of TPV with effective temperature.

\subsection{Adaptive thermal comfort model}

Monthly mean outdoor temperature was taken as $30^{\circ} \mathrm{C}$, and the comfort temperature was evaluated for each model. Adaptive comfort models proposed by ASHRAE Standard 55 [4] and EN15251 [32] are not suitable to predict comfort temperature for climatic conditions of Kozhikode, whereas the remaining three models proposed by Indraganti et al [33], Nguyen et al [10] and Toe and Kubota [34] may be used to predict comfort temperature. The adaptive comfort model proposed by Indraganti et al [33] is the best suitable model for climatic conditions of Kozhikode, Kerala, as the predicted comfort temperature $\left(29.2^{\circ} \mathrm{C}\right)$ is close to the comfort temperature $\left(30^{\circ} \mathrm{C}\right)$. Comfort temperature obtained based on Thermal Sensation Vote (TSV) was $30^{\circ} \mathrm{C}$ and is equal to monthly mean outdoor temperature. Adaptive 
Table 7. Comfort temperatures based on different adaptive comfort models.

\begin{tabular}{lccc}
\hline Adaptive comfort model & References & Comfort temperature $T_{\mathrm{c}}\left({ }^{\circ} \mathrm{C}\right)$ & Error $\left({ }^{\circ} \mathrm{C}\right)$ \\
\hline$T_{\mathrm{c}}=0.31 T_{\mathrm{o}}+17.38$ & Dear and Brager [4] & 26.68 & 3.32 \\
$T_{\mathrm{c}}=0.33 T_{\mathrm{o}}+18.8$ & Nicol and Humphreys [32] & 28.7 & 1.3 \\
$T_{\mathrm{c}}=0.26 T_{\mathrm{o}}+21.4$ & Indraganti et al $[33]$ & 29.2 & 0.8 \\
$T_{\mathrm{c}}=0.34 T_{\mathrm{o}}+18.83$ & Nguyen et al $[10]$ & 29.03 & 0.97 \\
$T_{\mathrm{c}}=0.57 T_{\mathrm{o}}+13.8$ & Toe and Kubota [34] & 30.9 & -0.9 \\
\hline
\end{tabular}

thermal comfort models along with the comfort temperatures obtained from each model and its deviation from the actual comfort temperature are tabulated in table 7.

\section{Conclusions}

Thermal comfort conditions of student residence zone of NIT Calicut, Kerala, India, were obtained. In the present study, it was clearly observed that PMV-PPD analysis based on Fanger's theory of thermal comfort failed in exact prediction of the comfort conditions in naturally ventilated hostels.

The preferred operative temperature based on Predicted Mean Vote (PMV) was found to be $27^{\circ} \mathrm{C}$ and neutral effective temperature was found to be $27.2^{\circ} \mathrm{C}$. The preferred operative temperature and neutral effective temperature obtained based on Thermal Sensation Vote (TSV) were 30 and $31.3^{\circ} \mathrm{C}$ respectively, whereas 29.4 and $30.4^{\circ} \mathrm{C}$ respectively were obtained in case of Thermal Preference Vote (TPV). Results obtained from Thermal Sensation Vote (TSV) and Thermal Preference Vote (TPV) were found to be in line with each other.

The acceptable range of operative temperature for $80 \%$ satisfaction was found to be $25.1-28.9^{\circ} \mathrm{C}$ in case of Predicted Mean Vote (PMV), $28.5-31.5^{\circ} \mathrm{C}$ in case of Thermal Sensation Vote (TSV) and $27.6-31.2^{\circ} \mathrm{C}$ in case of Thermal Preference Vote (TPV). Similarly, the acceptable range of effective temperature for $80 \%$ satisfaction was found to be $22.1-24.9^{\circ} \mathrm{C}$ in case of Predicted Mean Vote (PMV), 24.6-27 ${ }^{\circ} \mathrm{C}$ in case of Thermal Sensation Vote (TSV) and $23.9-26.7^{\circ} \mathrm{C}$ in case of Thermal Preference Vote (TPV).

A linear relationship, $\mathrm{PMV}=0.746 * \mathrm{TSV}+1.454$, was developed for obtaining Thermal Sensation Vote (TSV) in terms of Predicted Mean Vote (PMV) for warm humid climatic conditions of Kerala. Similarly a linear relationship, PMV $=0.852 * \mathrm{TPV}+1.239$, was developed for obtaining Thermal Preference Vote (TPV) in terms of Predicted Mean Vote (PMV) for warm humid climatic conditions of Kerala. The results obtained were in accordance with the adaptive thermal comfort theory. These results may provide some useful guidelines for the civil engineers and architectures for designing the hostels particularly in the state of Kerala.

An important outcome of the study is on the fact that the students of NIT Calicut are from various parts of the country. In NIT Calicut, $50 \%$ of students are from Kerala and remaining $50 \%$ are from other states of the country of which nearly $35 \%$ are from Andhra Pradesh. When the TSV of first-year students (Hostel A) was compared with TSV of final (fourth) year students (Hostels D and E), it was found that nearly $64 \%$ of first-year students felt comfort conditions whereas it was only $30 \%$ in case of final-year students. Hence, this study outlines that the comfort conditions are different for first-year and final-year students. First-year students felt comfortable since climatic conditions are hotter in Andhra Pradesh when compared with Kerala. However it is not same in case of final-year students since the students from other states were acclimatized to Kerala climatic conditions during their stay at hostels for the last 3 years. This highlights the importance of adaptive thermal comfort theory.

\section{Acknowledgements}

Authors would like to thank the R\&D wing of National Institute of Technology Calicut for funding this work under FRG and the administration and student community of National Institute of Technology Calicut for their technical support. 


\section{Appendix}

Two main questions posed to students are given below:

Express your thermal comfort by choosing one of the following options.

\begin{tabular}{|c|c|c|c|c|c|c|}
\hline & & & & & & \\
\hline Cold & Cool & $\begin{array}{c}\text { Slightly } \\
\text { cool }\end{array}$ & Neutral & $\begin{array}{c}\text { Slightly } \\
\text { warm }\end{array}$ & Warm & Hot \\
\hline
\end{tabular}

Which indoor condition would you prefer among the following?

\begin{tabular}{|l|l|l|}
\hline & & \\
\hline Cooler than present & Present condition & Hotter than present \\
\hline
\end{tabular}

ASHRAE thermal sensation scale:

\begin{tabular}{|c|c|c|c|c|c|c|}
\hline Cold & Cool & $\begin{array}{c}\text { Slightly } \\
\text { cool }\end{array}$ & Neutral & $\begin{array}{c}\text { Slightly } \\
\text { warm }\end{array}$ & Warm & Hot \\
\hline-3 & -2 & -1 & 0 & 1 & 2 & 3 \\
\hline
\end{tabular}

\section{References}

[1] Census 2011 Provisional populations totals. Office of the Registrar General and Census Commissioner, Ministry of Home Affairs, Delhi

[2] MHRD 2012 Report of the people on education. Ministry of Human Resource Development, Government of India, Delhi

[3] UGC 2011 Inclusive and qualitative expansion of higher education. University Grants Commission, New Delhi

[4] Dear R J D and Brager G S 2002 Thermal comfort in naturally ventilated buildings: revisions to ASHRAE Standard 55. Energy Build. 34: 549-561

[5] Nicol F 2004 Adaptive thermal comfort standards in the hothumid tropics. Energy Build. 36: 628-637

[6] Nicol J F and Humphreys M A 2002 Adaptive thermal comfort and sustainable thermal standards for buildings. Energy Build. 34: 563-572

[7] Fanger P O and Toftum J 2002 Extension of PMV model to non-air-conditioned buildings in warm climates. Energy Build. 36: 533-536

[8] Yao R, Li B and Liu J 2009 A theoretical adaptive model of thermal comfort-adaptive Predicted Mean Vote (aPMV). Build. Environ. 44: 2089-2096

[9] Romana F, Alfano A, Ianniello E and Palella B I 2013 PMVPPD and acceptability in naturally ventilated schools. Build. Environ. 67: 129-137

[10] Nguyen A T, Singh M K and Reiter S 2012 An adaptive thermal comfort model for hot humid South-East Asia. Build. Environ. 56: 291-300

[11] Liu J, Yao R and McCloy R 2012 A method to weight three categories of adaptive thermal comfort. Energy Build. 47: $312-320$
[12] Singh M K, Mahapatra S and Atreya S K 2010b Thermal performance study and evaluation of comfort temperatures in vernacular buildings of North-East India. Build. Environ. 45: 320-329

[13] Singh M K, Mahapatra S and Atreya S K 2011 Adaptive thermal comfort model for different climatic zones of Northeast India. Appl. Energy 88: 2420-2428

[14] Singh M K, Mahapatra S, Atreya S K and Givoni B 2010a Thermal monitoring and indoor temperature modeling in vernacular buildings of North-East India. Energy Build. 42: $1610-1618$

[15] Dili A S, Naseer M A and Varghese T Z 2010a Passive control methods of Kerala traditional architecture for a comfortable indoor environment: comparative investigation during various periods of rainy season. Build. Environ. 45: 2218-2230

[16] Dili A S, Naseer M A and Varghese T Z 2010b Passive environment control system of Kerala vernacular residential architecture for a comfortable indoor environment: a qualitative and quantitative analyses. Energy Build. 42: 917-927

[17] Dili A S, Naseer M A and Varghese T Z 2010c Thermal comfort study of Kerala traditional residential buildings based on questionnaire survey among occupants of traditional and modern buildings. Energy Build. 42: 2139-2150

[18] Dili A S, Naseer M A and Varghese T Z 2010d Passive control methods of Kerala traditional architecture for a comfortable indoor environment: a comparative investigation during winter and summer. Build. Environ. 45: 1134-1143

[19] Dili A S, Naseer M A and Varghese T Z 2011 Passive control methods for a comfortable indoor environment: comparative investigation of traditional and modern architecture of Kerala in summer. Energy Build. 43: 653-664 
[20] Priya R S, Sundarraj M C, Radhakrishnan S and Vijayalakshmi L 2012 Solar passive techniques in the vernacular buildings of coastal regions in Nagapattinam, TamilNadu, India: a qualitative and quantitative analysis. Energy Build. 49: $50-61$

[21] Indraganti M 2010a Understanding the climate sensitive architecture of Marikal, a village in Telangana region in Andhra Pradesh, India. Build. Environ. 45: 2709-2722

[22] Indraganti M 2010b Adaptive use of natural ventilation for thermal comfort in Indian apartments. Build. Environ. 45: 1490-1507

[23] Indraganti M 2010c Thermal comfort in naturally ventilated apartments in summer: findings from a field study in Hyderabad, India. Appl. Energy 87: 866-883

[24] Indraganti M 2010d Using the adaptive model of thermal comfort for obtaining indoor neutral temperature: findings from a field study in Hyderabad, India. Build. Environ. 45: $519-536$

[25] Indraganti M 2011 Thermal comfort in apartments in India: adaptive use of environmental controls and hindrances. Renew. Energy 36: 1182-1189

[26] Indraganti M, Ooka R and Rijal H B 2013 Field investigation of comfort temperature in Indian office buildings: a case of Chennai and Hyderabad. Build. Environ. 65: 195-214

[27] Dhaka S, Mathur J and Garg V 2012 Combined effect of energy efficiency measures and thermal adaptation on air- conditioned building in warm climatic conditions of India. Energy Build. 55: 351-360

[28] Dhaka S, Mathur J, Wagner A, Agarwal G D and Garg V 2013 Evaluation of thermal environmental conditions and thermal perception at naturally ventilated hostels of undergraduate students in composite climate. Build. Environ. 66: 42-53

[29] Deb C and Ramachandraiah A 2010 Evaluation of thermal comfort in a rail terminal location in India. Build. Environ. 45: $2571-2580$

[30] Chithra V S and Nagendra S M S 2012 Indoor air quality investigations in a naturally ventilated school building located close to an urban roadway in Chennai, India. Build. Environ. 54: 159-167

[31] Mishra A K and Ramgopal M 2015 An adaptive thermal comfort model for the tropical climatic regions of India (Koppen climate type A). Build. Environ. 85: 134-143

[32] Nicol F and Humphreys M 2010 Derivation of the adaptive equations for thermal comfort in free-running buildings in European standard EN15251. Build. Environ. 45(1): 11-17

[33] Indraganti M, Ooka R, Rijal H B and Brager G S 2014 Adaptive model of thermal comfort for offices in hot and humid climates of India. Build. Environ. 74: 39-53

[34] Toe D H C and Kubota T 2013 Development of an adaptive thermal comfort equation for naturally ventilated buildings in hot-humid climates using ASHRAE RP-884 database. Front. Architect. Res. 2: 278-291 